\section{Archivos \\ de Cardiología de México}

IMÁGENES EN CARDIOLOGÍA

\title{
Incidentaloma cardiaco en tiempos de COVID-19: divertículo ventricular
}

\author{
Cardiac incidentaloma in times of COVID-19: ventricular diverticulum \\ Javier Urmeneta-Ulloa ${ }^{1 *}$, José A. Cabrera ${ }^{1}$, Ana Álvarez-Vázquez² ${ }^{2}$ Esther Merino-Lanza ${ }^{1}$ y \\ Vicente Martínez De Vega² \\ ${ }^{1}$ Servicio de Cardiología; ${ }^{2}$ Servicio de Radiología. Hospital Universitario Quirónsalud, Madrid, España
}

Varón de 56 años con enfisema pulmonar y episodios previos de neumotórax espontáneos secundarios a bullas subpleurales. Acude a nuestro centro por clínica de fiebre $38.5^{\circ} \mathrm{C}$, disnea de reposo y tos seca. En la radiografía de tórax se observa patrón intersticial bilateral, por lo que ingresa con sospecha de neumonía bilateral por COVID-19, posteriormente confirmada con PCR positiva. Se completa el estudio con tomografía

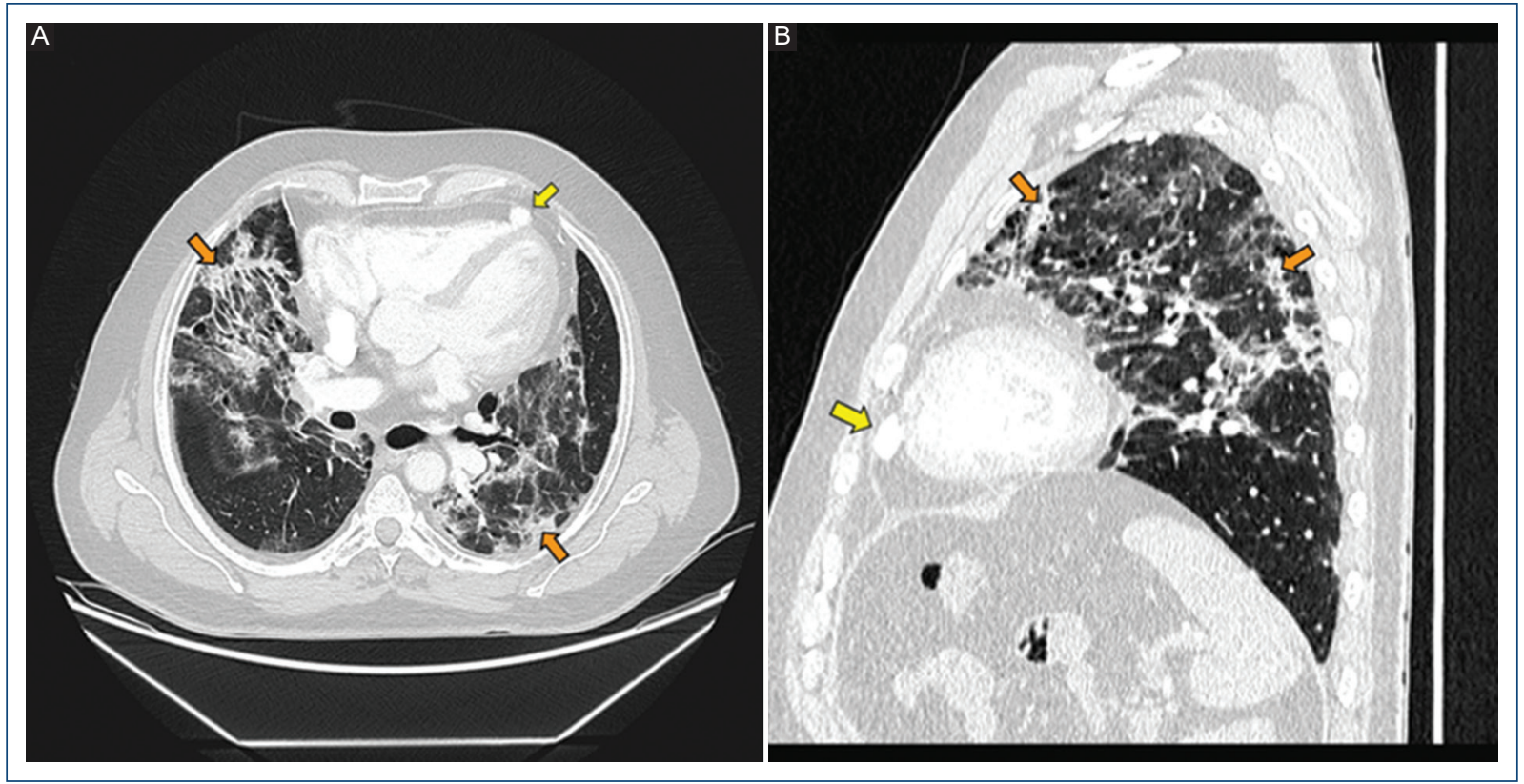

Figura 1. Infiltrados pulmonares en vidrio deslustrado y consolidaciones de distribución periféricas (flecha naranja) en relación con neumonía por COVID-19. Se evidencia una imagen sacular pediculada de $19 \times 12 \mathrm{~mm}$ en el ápex del ventrículo derecho sugestiva de divertículo (flecha amarilla).

Correspondencia:

*Javier Urmeneta-Ulloa

E-mail: javierurmeneta@ hotmail.com
Fecha de recepción: 14-06-2020

Fecha de aceptación: 21-08-2020 DOI: 10.24875/ACM.20000282
Disponible en internet: 05-03-2021 Arch Cardiol Mex. 2021;91(Supl):126-128 www.archivoscardiologia.com

1405-9940 / ( ) 2020 Instituto Nacional de Cardiología Ignacio Chávez. Publicado por Permanyer. Este es un artículo open access bajo la licencia CC BY-NC-ND (http://creativecommons.org/licenses/by-nc-nd/4.0/). 


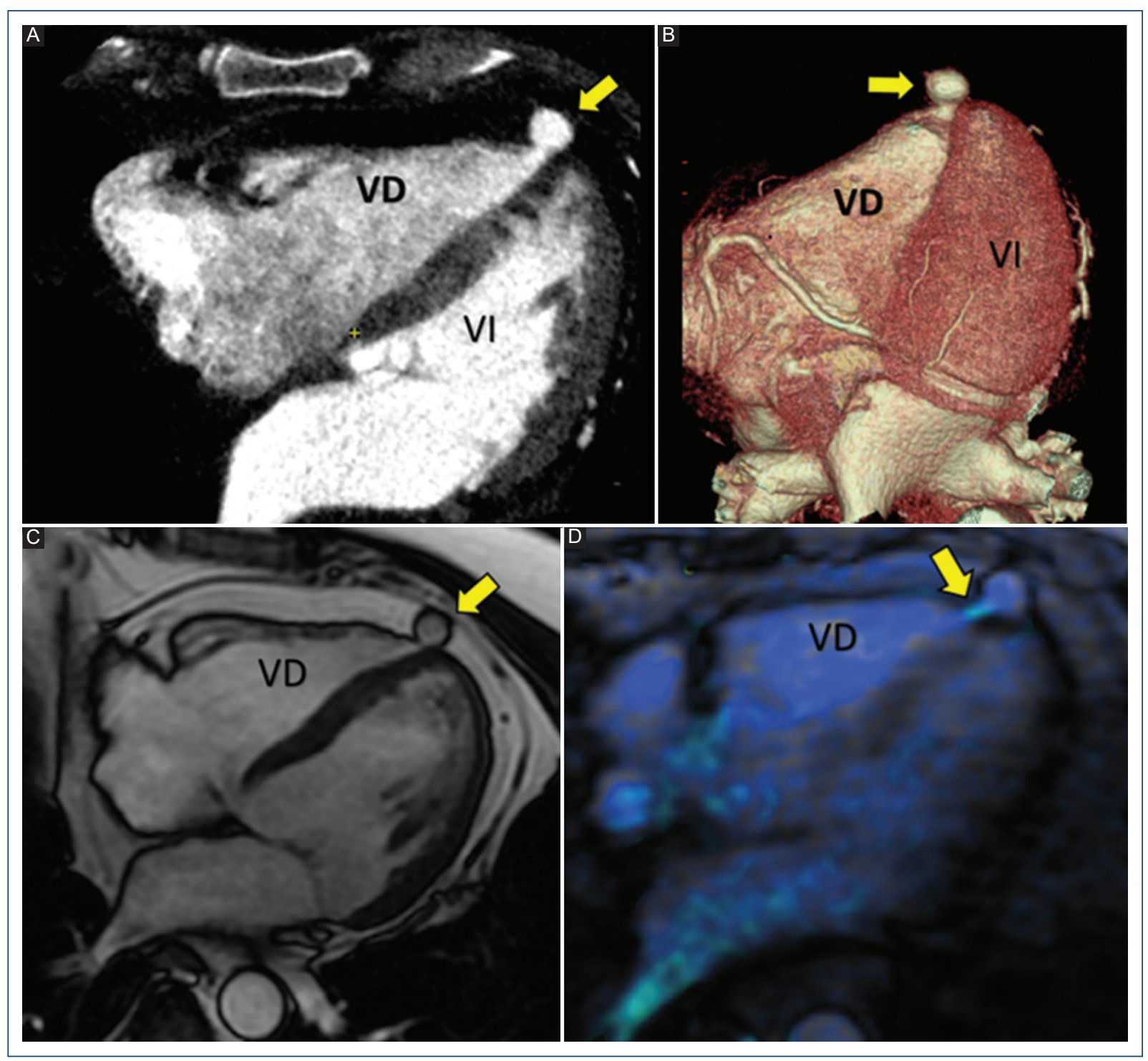

Figura 2. A y B: Estudio con tomografía computarizada cardiaca, excluyendo cardiopatía isquémica y confirmando el diagnóstico incidental de divertículo apical de ventrículo derecho (flecha amarilla). C y D: resonancia magnética cardiaca para descartar una miocardiopatía, valorando igualmente el divertículo y el comportamiento funcional del flujo a su través mediante técnica 4DFlow (Vid. 1-2) (flecha amarilla).

VD: ventrículo derecho; VI: ventrículo izquierdo.

computarizada pulmonar (Fig. 1), en la que se objetivan infiltrados pulmonares en vidrio deslustrado y consolidaciones de distribución periféricas en relación con neumonía por COVID-19. Incidentalmente se evidencia una imagen sacular pediculada de $19 \times 12 \mathrm{~mm}$ en el ápex del ventrículo derecho sugestiva de divertículo. Ante la presencia de disfunción ventricular izquierda en la ecocardiografía, se completa el estudio con tomografía computarizada cardiaca (Fig. 2 A y B), excluyendo cardiopatía isquémica y confirmando el diagnóstico incidental de divertículo apical de ventrículo derecho. Finalmente, se lleva a cabo una resonancia magnética cardiaca (Fig. 2 C y D) para descartar una miocardiopatía, valorando igualmente el divertículo y el comportamiento funcional del flujo a su través mediante técnica 4DFlow (Vid. 1-2) (Fig. 2 D. Respecto a la disfunción ventricular izquierda, se instauró tratamiento farmacológico con un betabloqueante y un inhibidor del sistema renina angiotensina aldosterona, con mejoría de la función ventricular en el seguimiento realizado. Por otro 
lado, respecto al divertículo, por tratarse de un hallazgo incidental y ante la ausencia de eventos embólicos y taquiarritmias, se adoptó un manejo conservador, sin complicaciones hasta el momento actual.

El divertículo ventricular es una malformación congénita cardiaca de escasa frecuencia $(0.6 \%$ en el ventrículo derecho $)^{1}$, caracterizada por una protrusión localizada de la pared ventricular. Su localización más frecuente es en el ápex del ventrículo izquierdo ${ }^{2,3}$, y en la edad adulta su diagnóstico suele ser incidental. Consiste en una cavidad que comunica con la cámara ventricular a través de un cuello estrecho, de morfología circular y tamaño variable $(0.5-9 \mathrm{~cm})^{2}$. Suele presentarse de forma aislada, en el $30 \%$ de los casos, mientras que en el $70 \%$ restante se asocia con otras anomalías congénitas ${ }^{3}$. Característicamente compromete todas las capas del corazón (miocardio, endocardio y pericardio) y se contrae de manera sincrónica en sístole con la cámara cardiaca correspondiente ${ }^{3}$. Si bien se han reportado casos de complicaciones, en general presenta un curso benigno, y en los casos asintomáticos la tendencia es un tratamiento conservador.

\section{Conflicto de intereses}

Ninguno.

\section{Financiamiento}

La presente investigación no ha recibido ninguna beca específica de agencias de los sectores público, comercial o sin ánimo de lucro.

\section{Responsabilidades éticas}

Protección de personas y animales. Los autores declaran que para esta investigación no se han realizado experimentos en seres humanos ni en animales.

Confidencialidad de los datos. Los autores declaran que han seguido los protocolos de su centro de trabajo sobre la publicación de datos de pacientes.

Derecho a la privacidad y consentimiento informado. Los autores declaran que en este artículo no aparecen datos de pacientes.

\section{Bibliografía}

1. Nakazono T, Jeudy J, White C. Left and right ventricular diverticula: incidence and imaging findings on 256-slice multidetector computed tomography. J Thorac Imaging. 2012;27:179-83.

2. Courtis J, Liendo R, Juaneda E, Tibaldi J. Divertículo fibroso del ventrículo derecho y derrame pericárdico en una paciente adulta. Un raro hallazgo. Rev Fed Arg Cardiol. 2013;42:215-8.

3. Bhardwaj B, Kumar S, Webel R, Guatam S, Chockalingam A. Multimodality detection of multiple left ventricular diverticula: a case report and brief review of the literature. Echocardiography. 2019;36:184-8. 